\title{
Impact of the -216G/T Polymorphism on the Sp1 and Epidermal Growth Factor Receptor Interaction in Non-Small Cell Lung Carcinoma
}

\author{
A. Mesli-Mostafa1 ${ }^{*}$, A. Kacimi², B. Merad ${ }^{3}$, N. Belblidia², T. Sahraoui' ${ }^{1}$, F.-Z. El Kebir ${ }^{1}$ \\ ${ }^{1}$ Biology of Development and Differentiation Laboratory, University of Oran 1, Ahmed Benbella, Algeria \\ ${ }^{2}$ Pathological Anatomy Service, Mohammed Seghir Nekkache Hospital, Algiers, Algeria \\ ${ }^{3}$ Laboratory of Anatomy and Cytopathology, Oran, Algeria \\ Email: *meslimesliamel@yahoo.com
}

Received 18 January 2016; accepted 4 July 2016; published 7 July 2016

Copyright (C) 2016 by authors and Scientific Research Publishing Inc.

This work is licensed under the Creative Commons Attribution International License (CC BY). http://creativecommons.org/licenses/by/4.0/

(c) $\underset{\mathrm{EY}}{\mathrm{F}}$ Open Access

\section{Abstract}

The epidermal growth factor receptor is central to the growth, differentiation and the mobility of normal and cancer cells. Notably, EGFR plays an important role in non-small cell lung carcinoma development. Two known nucleotide variants in EGFR promoter at position -216 (G > T) and -191 $(C>A)$ are known to influence promoter activity. The transcription factor Sp1 (Specificity protein 1) binds with higher affinity the $T$ allele at position -216 which results in $30 \%$ increased transcriptional activity of EGFR. Sequencing of EGFR promoter region and exon 1 in 18 patients with pulmonary carcinoma revealed that $-216 \mathrm{G} / \mathrm{T}$ variant was associated with $58.82 \%$ of NSCLC patients especially those with squamous carcinoma, with predominance of homozygote (T/T) variants. Strikingly, the $-\mathbf{1 9 1 C}$ /A polymorphism was detected in $11.11 \%$ of patients having a pulmonary carcinoma with the predominance of homozygote $(\mathrm{C} / \mathrm{C})$ variants. The distribution analysis of the four haplotypes (G-C, G-A, T-C and T-A) and the diplotype (G-C/T-C) of -216G/T and -191C/A polymorphisms, revealed a clear predominance of $\mathrm{T}-\mathrm{C}$ haplotype (216T-191C) in squamous cell carcinoma. The G-C and G-A haplotypes have a lesser distribution while the T-A haplotype is non-existent. The incidence of (G-C/T-C) diplotype is more important than the G-A haplotype in all the studied cases. Our results are strongly correlated with the data of Caucasian population.

\section{Keywords}

NSCLC, EGFR, -216G/T, Sp1, -191C/A

\footnotetext{
${ }^{*}$ Corresponding author.
} 


\section{Introduction}

The epidermal growth factor receptor (EGFR) is a $170 \mathrm{KDa}$ transmembrane glycoprotein with a tyrosine kinase activity, encoded by a gene located on human chromosome 7p 12.1-12.3. EGFR is an ubiquitously expressed tyrosine kinase that plays a crucial role in cell proliferation, differentiation, mobility and the survival of normal and tumor cells [1] [2]. EGFR is over-expressed in 30\% of human primary tumors and its activity correlates to tumor stage, survival and the response to chemotherapy [1]. Thus, most of patients present with a local advanced or metastatic stage and a survival period of five years in $15 \%$ of patients having lung carcinoma [3]. The EGFR gene has a G-C rich regulatory region devoid of TATA or CAAT box.

The regulatory process of EGFR is complex and is based on interactions between the transcriptional factors binding multiple sites found in the promoter region [4], an intronic enhancer element and two enhancer cooperative regions located near exon 1 as well as a CA dinucleotid repetition polymorphic site located also in intron 1 [5] [6]. The basal transcription of EGFR is essentially regulated by the transcription factor Sp1 (Specificity protein 1 or Sephacryl and phosphocellulose columns), which binds at least four known binding sites. Sp1 is one of the Sp/KLF (Kruppel like factor) transcription factors binding GC sites, inducing regulation of gene without TATA box. It's also able to enhance the SV-40 (Simian Virus-40) promoter at GC rich sites [7]-[12]. The sequence analysis of the regulatory region of EGFR has revealed the presence of a functional Single Nucleotide Polymorphism (SNP) located at the recognition site of Sp1. This -216G/T SNP increases the promoter activity by 30\% [13]. Recent studies have shown that p38-MAPK induces the phosphorylation of Sp1 and then increases the DNA binding activity after epidermal growth factor (EGF) stimulation [14] [15]. The blocking or loss of activity of p38-MAPK decreases the binding affinity of Sp factors to the promoter elements at -245 and -240 sites [15]. Recent studies have also shown that histones desacetylases inhibitors (HADCi) induce the dissociation of Sp1 from the EGFR promoter [16]. Besides data of the EGFR gene regulation, there is few data about the variants of the 5' regulatory region of the EGFR. Thus, we sequenced the promoter region of EGFR in Algerian patients with NSCLC and reported two polymorphisms implicated in the regulation of the expression of the EGFR.

\section{Material and Methods}

\subsection{Tumor Samples}

This study reports 17 patients with non small cell lung carcinoma (NSCLC), one patient with small cell lung carcinoma (SCLC), and a healthy patient. Patients' specimens were obtained from either the Laboratory of Anatomopathology of Mohamed Seghir Nekkache Hospital of Algiers or from the Laboratory of Anatomopathology of west Algeria with consents.

All biopsies were performed during surgical thoracic resection. The tumor samples embedded in paraffin were kept away from light and humidity at $+4^{\circ} \mathrm{C}$. The clinical data including age, gender and anatomopathological diagnosis have been obtained for all patients as well.

\subsection{Histopathological Diagnosis}

The histopathological analysis and the definition of the score of lung tumors have been performed in accordance with the data published in the International System for Staging Lung Cancer [17]. All clinical diagnosis provided by the hospital have been evaluated and confirmed according to the classification established by the World Health Organization (WHO) for lung cancers. Some immunostainings using EGFR and Cytokeratin 5/6 antibodies, have been performed using the Envision+ kit (Dako Cytomation; Denmark) at the Laboratory of Biology of Development and Differentiation at the University of Oran 1 Ahmed Benbella, Algeria, to confirm the differential diagnosis of NSCLC.

\subsection{Extraction and Sequencing}

The genomic study was performed at Nemours Biomolecular Core Laboratory located in the Alfred I du Pont Hospital for Children (Wilmington, DE, USA).

The genomic DNA was extracted from formalin-fixed and paraffin-embedded (FFPE) tissues of primary tumors using the Puregene Buccal Cell Kit (Qiagen; USA). Samples were subjected overnight to an enzymatic di- 
gestion with proteinase $\mathrm{K}$ (Puregene; USA) at $37^{\circ} \mathrm{C}$. The lysed samples were treated with RNase and the fraction containing proteins precipitated. The DNA was purified after precipitation with isopropanol solution in the presence of glycogen $(20 \mathrm{mg} / \mathrm{ml})$. DNA resuspension was performed using Tris-EDTA solution (TE 10:01).

The primers used to amplify a $245 \mathrm{bp}$ sequence in the promoter region of interest are follows (5'-GCGCAGCGCGGCCGCAGCA-3') and (5'-GCATCGCTGCTCCCCGAAGA-3'). About 100 to $150 \mathrm{ng}$ of genomic DNA was incubated in $25 \mu \mathrm{l}$ reaction containing $0.15 \mu \mathrm{l}$ of Taq Polymerase (Qiagen; USA). The DNA amplification included a preheating step at $98^{\circ} \mathrm{C}$ during $5 \mathrm{~min}$ followed by 45 cycles for $30 \mathrm{sec}$ at $98^{\circ} \mathrm{C}, 30 \mathrm{sec}$ at $63^{\circ} \mathrm{C}$ and $1 \mathrm{~min}$ at $72^{\circ} \mathrm{C}$. PCR products were purified with the Qiaquik PCR Purification Kit (Qiagen; USA) and sequenced using the BigDye Terminator v3.1 Cycle Sequencing Kit (Thermofisher; USA) followed by treatment with sodium dodecyl sulfat (SDS) solution at $0.2 \%$, and purification using Edge BioSystems Performa DTR Gel Filtration Cartridges (USA). The sequence analysis was performed on the ABI 3130X Genetic Analyzer (USA) using standard operating protocols.

\section{Results}

Sequence analysis of the EGFR promoter region in lung carcinoma subjects identified distinct haplotypes defined by variants at position -216G/T and -191C/A (Figure 1). Variants at the $-216 \mathrm{Sp} 1$ binding site was observed in $58.82 \%$ of the patients with NSCLC. At position $-216 \mathrm{G} / \mathrm{T}, 72.72 \%$ of patients with squamous carcinomas carry the $\mathrm{T}$ allele with $75 \%$ of the tumors being homozygous $(\mathrm{T} / \mathrm{T})$ while $25 \%$ are heterozygous $(\mathrm{G} / \mathrm{T})$. Only $40 \%$ of patients with adenocarcinoma carry the $-216 \mathrm{G} / \mathrm{T}$ variant, while one patient with SCLC carried the

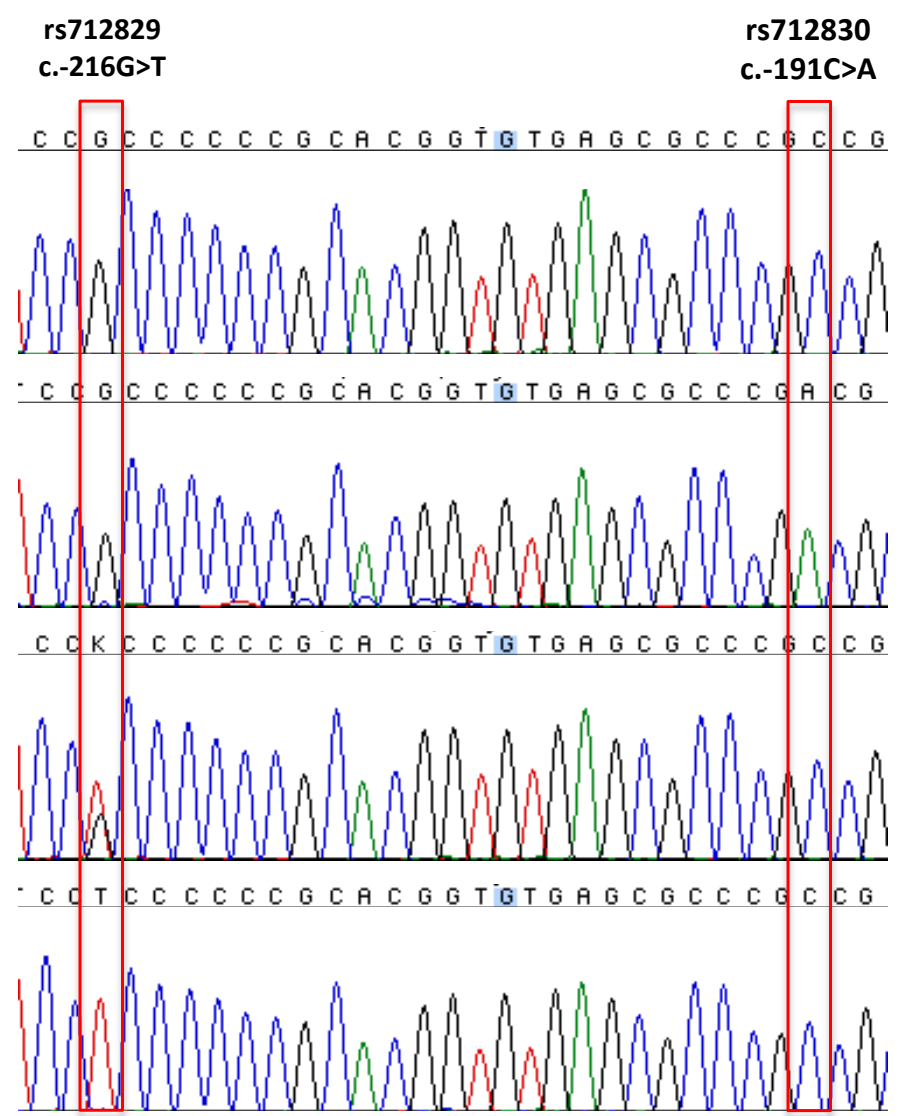

Figure 1. The highlight of two polymorphisms -216G/T and -191C/A, located on the regulatory region of the gene encoding for epidermal growth factor receptor (EGFR). The alignment of the 5 'sequences resulting from the amplification of the exon 1 fraction and the promoter show the presence of the polymorphism $-216 \mathrm{G} / \mathrm{T}$ located in the EGFR promoter binding site of Sp1. The second polymorphism -191C/A is located $4 \mathrm{pb}$ upstream of one of the EGFR transcription initiation sites. 
G allele. About $11.11 \%$ of male patients with pulmonary carcinomas carried a variant at -191 position. The homozygous genotype (A/A) was found in a patient with SCLC and a patient with squamous carcinoma both of them marked with the absence of a $\mathrm{T}$ allele at $\mathrm{Sp} 1$ binding site.

The distribution of the four haplotypes (G-C[-216G-191C], G-A[-216G-191A], T-C[-216T-191C] and T-A [-216T-191A] and the diplotype (G-C/T-C) in the EGFR promoter region revealed a clear predominance (38.88\%) of the haplotype T-C in all lung cancers (Table 1), with $41.17 \%$ in the NSCLC. A great predominance of the haplotype $\mathrm{T}-\mathrm{C}$ has been found in squamous carcinoma with a percentage of $54.54 \%$. A less incidence of the haplotype G-C (33.33\%) has been reported in all of the patients with lung carcinoma with a low percentage $(18.18 \%)$ described in squamous carcinoma patients. The incidence of the haplotype G-A is in the $3^{\text {rd }}$ position $(11.11 \%)$ and seems to be more frequent in squamous carcinomas $(9.09 \%)$. The T-A haplotype is non-existent in all lung cancers.

The (G-C/T-C) diplotype distribution analysis revealed a percentage of $16.66 \%$, more important than G-A haplotype distribution in all lung cancers. It's important to highlight that the highest incidence has been reported in squamous cell carcinoma (18.18\%).

\section{Discussion}

The EGFR basal transcription is regulated by the Sp1 factor [7] [8]. The substitution of a guanine by a thymine in $-216 \mathrm{G} / \mathrm{T}$ position corresponding to the recognition site of Sp1 increases the EGFR promoter activity by $30 \%$ [10]. The results show the presence of the variation $-216 \mathrm{G} / \mathrm{T}$ in $58.82 \%$ of patients with NSCLC, especially those having squamous carcinoma.

The immunostaining of adenocarcinoma lung tissues by the EGFR antibodies revealed a medium staining intensity, contradicting the phenomenon of EGFR over-expression. The immunostaining of EGFR combined to the cytokeratins 5/6 and Thyroid Transcription factor-1 (TTF1) are mainly used in the differential diagnosis of NSCLC. Furthermore, most of patients with adenocarcinoma have the variation G216T and revealed a moderately intense staining of the CK5/6. These results could explain the medium intensity staining obtained for EGFR and lead to the hypothesis of adenosquamous carcinoma. The over-expression of EGFR has been observed in a patient with lung adenocarcinoma carrying the homozygous allele $\mathrm{T}$ at the -216 position. This result could be explained by the increasing activity of the EGFR promoter by at least 30\% [13]. Numerous data confirm the necessity of the Sp1 factor in the EGFR gene transcription and suggest a regulatory role not dependent of the cell type and the expression rate of EGFR. Nevertheless, it may be possible that other cis-activating functional elements could also cooperate with the variation $-216 \mathrm{G} / \mathrm{T}$ in vivo. The $-216 \mathrm{G} / \mathrm{T}$ polymorphism is not related to the other polymorphisms located in the promoter region or the (CA)n polymorphism in intron 1 and the intron's microsatellites [13].

The distribution analysis of the variation $-216 \mathrm{G} / \mathrm{T}$ in the squamous lung carcinoma, revealed an important $-216 \mathrm{G} / \mathrm{T}$ polymorphism frequency with a rate of $75 \%$ of homozygous $(\mathrm{T} / \mathrm{T})$ tumors and $25 \%$ of heterozygous (G/T) tumors. A lot of data show the existence of the binding affinity variation of nuclear proteins on the Splconsensus sequence. Thus, the measure of the binding efficiency of the $\mathrm{Sp} 1$ protein on the T allele seems to be highly more significant than for the $G$ allele [13]. This could explain the EGFR expression rate through the results describing the frequent distribution of the $\mathrm{T}$ allele in squamous lung carcinoma. The absence of $\mathrm{Sp} 1 \mathrm{site}$ in patient with SCLC correlated with the differential expression of EGFR compared to NSCLC.

Table 1. Distribution of four haplotypes (G-C, G-A, T-C and T-A) and the diplotype (G-C/T-C) of the -216G/T and -191C/A polymorphisms of the EGFR promoter in lung carcinoma of the North-African patients.

\begin{tabular}{cccc}
\hline Haplotypes -216G/T and -191C/A & Lung Cancers (\%) & NSCLC (\%) & Squamous Carcinoma (\%) \\
G-C & 33.33 & 35.29 & 18.18 \\
G-A & 11.11 & 5.88 & 9.09 \\
T-C & 38.88 & 41.17 & 54.54 \\
T-A & 0 & 0 & 0 \\
Diplotype G-C/T-C & 16.66 & 17.64 & 18.18 \\
\hline
\end{tabular}


The healthy patient is homozygote for the $\mathrm{T}$ allele, thus justifying the important process of regulation of the EGFR promoter even in absence of regulation of lung hyperplasia. However, it is important to note that most of patients with lung adenocarcinoma were not homozygote for the $\mathrm{T}$ allele, and this fact is in contradiction with the high expression level of EGFR mainly over-expressed in this kind of histological type.

The polymorphism -216G/T corresponds to one of the fourth recognition sites of Sp1, while the -191C/A polymorphism is located upstream of the sixth transcription initiation sites [8] [9]. This last data could not exclude the possibility of a potential regulatory action of -191C/A polymorphism on the EGFR promoter [13]. The sequencing of the promoter region revealed the presence of the -191C/A polymorphism in $11.11 \%$ of masculine patients with lung carcinoma having homozygote alleles (A/A). These patients revealed the absence of the $-216 \mathrm{G} / \mathrm{T}$ polymorphisms. This last data leads to think that the presence of the $-191 \mathrm{C} / \mathrm{A}$ polymorphism (homozygote (A/A)) seems to be substitutive to the $-216 \mathrm{G} / \mathrm{T}$ polymorphism. Our results describe the presence of the polymorphism -191C/A in Algerian cancer population. This is in accordance with the data of Caucasian population. Whereas no variation -191C/A has been detected in Asiatic and afro-American population. The assessment of EGFR allelic transcription level in the fibroblast cell lines bearing the (G-C/T-C) diplotype for the G216T and C191A polymorphisms, has shown that the expression of mRNA bearing the T-C haplotype were stronger than the level of expression of the G-C haplotype $(\mathrm{P}<0.02)$. This result demonstrates that the variant $-216 \mathrm{G} / \mathrm{T}$ has a substantial impact on the EGFR transcription in vivo [13].

EGFR possesses a major initiation transcription site located at the -260 position [8] [9], giving evidence of the presence of G216T and C191A sites in the resulting mRNA sequences. Assessment of EGFR expression in three cell lines revealed a high expression in MDA-MB-231 cell line (haplotype T-C), six-fold higher than HEK-293 cell line (diplotype G-C/T-C), while the lowest rate has been observed in the MCF-7 cell line (haplotype G-C) [13]. Some experiments revealed the predominance of the T-C haplotype in squamous carcinomas and a high frequency of the G-C/T-C diplotype compared with all lung carcinomas. This previous data is correlated with the aggressive phenotype and the poor prognosis of squamous carcinomas, caused essentially by the EGFR over-expression leading to the carcinogenesis process by apoptosis inhibition and cell cycle activation [2].

A low incidence $(11.11 \%$ ) has been described for the G-A haplotype in our study for all lung carcinomas. It seems to be in accordance with the level described of the Caucasian population (18.2\%), but not in the afro-American and Asiatic population ( $0 \%$ ). We haven't detected the T-A haplotype in the Algerian patients. This last result is perfectly correlated with that one obtained for Caucasian, afro-American and Asiatic population [13].

\section{Conclusions}

The Sp1 factor regulates the EGFR basal transcription by increasing its activity about $30 \%$ to $40 \%$, due to the presence of the $-216 \mathrm{G} / \mathrm{T}$ polymorphism. The $\mathrm{T}$ allele is frequently found in tumors of squamous carcinoma and binds more efficiently Sp1 than the G allele. This could reveal a very bad prognosis in absence of direct or indirect inhibition of the Sp1 factor and inform about the anti-tumoral medication efficiency.

There is a hypothesis about synergetic role of the $-216 \mathrm{G} / \mathrm{T}$ and $-191 \mathrm{C} / \mathrm{A}$ polymorphisms. Maybe, they could induce lung carcinoma development since a significant incidence of the haplotype T-C has been reported particularly in the squamous carcinoma. But, it still important to characterize and confirm the regulatory action in tumor cells because of the high incidence of T-C polymorphisms in the healthy Caucasian population.

\section{Acknowledgements}

A special thank is dedicated to the Doctor Noureddine MELIKECHI, Dean of the College of Mathematics, Natural Sciences and Technology of Delaware State University, Dover, USA, for all the help and the hospitability.

Thank you to the Doctor Katia SOLCHURCH and Miss Deborah STABLEY from the Nemours Bimolecular Core Laboratory for sequencing support, help and advices.

I thank the Professor Ahmed KACIMI and the Doctor Bahia MERAD for samples and for all the help that I had. I thank also Mister HALIMIA Hakim, laboratory technician in the Anatomical Pathology Service of the Mohammed Seghir Nekkache Hospital, Algeria, for its human values.

I am very grateful to the Doctor Eric KMIEC, Chairman of the Chemistry Department of Delaware State University, Dover, USA, for his welcome, his help and advices. 


\section{References}

[1] Grandis, J.R. and Sok, J.C. (2004) Signaling through the Epidermal Growth Factor Receptor during the Development of Malignancy. Pharmacology \& Therapeutics, 102, 37-46. http://dx.doi.org/10.1016/j.pharmthera.2004.01.002

[2] Brandt, B., Meyer-Staeckling, S., Schmidt, H., Agelopoulos, K. and Buerger, H. (2006) Mechanisms of EGFR Gene Transcription Modulation; Relationship to Cancer Risk and Therapy Response. Clin Cancer Res, 12, 7252-7260. http://dx.doi.org/10.1158/1078-0432.CCR-06-0626

[3] Rothschild, S., Betticher, D.C., Ochsenbein, A., Stahel, R., Bubendorf, L., Gugger, M., Brutsche, M., Pless, M. and Gautschi, O. (2010) Importance de l'histologie pour le traitement du carcinome bronchique non à petites cellules à un stade avancé. Forum Med Suisse, 10, 384-388.

[4] Ishii, S., Xu, Y.-H., Stratton, R.H., Roe, B.A., Merlino, G.T. and Pastan, I. (1985) Characterization and Sequence of $\mathrm{t}$ he Promoter Region of the Human Epidermal Growth Factor Receptor Gene. Proceedings of the National Academy of Sciences of the United States of America, 82, 4920-4924. http://dx.doi.org/10.1073/pnas.82.15.4920

[5] Maekawa, T., Imamoto, F., Merlino, G.T., Pastan, I. and Ishii, S. (1989) Cooperative Function of Two Separate Enhancers of the Human Epidermal Growth Factor Receptor Protooncogene. The Journal of Biological Chemistry, 264, 5488-5494.

[6] McInerney, J.M., Wilson, M.A., Strand, K.J. and Chrysogelos, S.A. (2001) A Strong Intronic Enhancer Element of the EGFR Gene Is Preferentially Active in High EGFR Expressing Breast Cancer Cells. Journal of Cellular Biochemistry, 80, 538-549. http://dx.doi.org/10.1002/1097-4644(20010315)80:4<538::AID-JCB1008>3.0.CO;2-2

[7] Kageyama, R., Merlino, G.T. and Pastan, I. (1988) A Transcription Factor Active on the Epidermal Growth Factor Receptor Gene. Proceedings of the National Academy of Sciences of the United States of America, 85, 5016-5020. http://dx.doi.org/10.1073/pnas.85.14.5016

[8] Kageyama, R., Merlino, G.T. and Pastan, I. (1988) Epidermal Growth Factor (EGF) Receptor Gene Transcription. Requirement for Sp1 and an EGF Receptor-Specific Factor. The Journal of Biological Chemistry, 263, 6329-6336.

[9] Johnson, A.C., Ishii, S., Jinno, Y., Pastan, I. and Merlino, G.T. (1988) Epidermal Growth Factor Receptor Gene Promoter. Deletion Analysis and Identification of Nuclear Protein Binding Sites. The Journal of Biological Chemistry, 263, 5693-5699.

[10] Dynan, W.S. and Tjian, R. (1983) Isolation of Transcription Factors that Discriminate between Different Promoters Recognized by RNA Polymerase II. Cell, 32, 669-680. http://dx.doi.org/10.1016/0092-8674(83)90053-3

[11] Dynan, W.S. and Tjian, R. (1983) The Promoter-Specific Transcription Factor Sp1 Binds to Upstream Sequences in the SV40 Early Promoter. Cell, 35, 79-87. http://dx.doi.org/10.1016/0092-8674(83)90210-6

[12] Macleod, D., Charlton, J., Mullins, J. and Bird, A.P. (1994) Sp1 Sites in the Mouse Aprtgene Promoter Are Required to Prevent Methylation of the CpGisland. Genes \&Development, 8, 2282-2292. http://dx.doi.org/10.1101/gad.8.19.2282

[13] Liu, W., Innocenti, F., Wu, M.H., et al. (2005) A Functional Common Polymorphism in a Sp1 Recognition Site of the Epidermal Growth Factor Receptor Gene Promoter. Cancer Research, 65, 46-53.

[14] Chu, S. and Ferro, T.J. (2005) Sp1: Regulation of Gene Expression by Phosphorylation. Gene, 348, 1-11. http://dx.doi.org/10.1016/j.gene.2005.01.013

[15] Xu, K. and Shu, H.K. (2007) EGFR Activation Results in Enhanced Cyclooxygenase-2 Expression through p38 Mitogen-Activated Protein Kinase-Dependent Activation of the Sp1/Sp3 Transcription Factors in Human Gliomas. Cancer Research, 67, 6121-6129. http://dx.doi.org/10.1158/0008-5472.CAN-07-0141

[16] Chou, C.-W., Wu, M.-S., Huang, W.-C. and Chen, C.-C. (2011) HDAC Inhibition Decreases the Expression of EGFR in Colorectal Cancer Cells. PLoS One, 6, e18087. http://dx.doi.org/10.1371/journal.pone.0018087

[17] Mountain, C.F. (1997) Revisions in the International System for Staging Lung Cancer. Chest, 111, 1710-1717. http://dx.doi.org/10.1378/chest.111.6.1710 


\section{Submit or recommend next manuscript to SCIRP and we will provide best service for you:}

Accepting pre-submission inquiries through Email, Facebook, Linkedin, Twitter, etc A wide selection of journals (inclusive of 9 subjects, more than 200 journals)

Providing a 24-hour high-quality service

User-friendly online submission system

Fair and swift peer-review system

Efficient typesetting and proofreading procedure

Display of the result of downloads and visits, as well as the number of cited articles

Maximum dissemination of your research work

Submit your manuscript at: http://papersubmission.scirp.org/ 